\title{
Study on Meconium stained fluid-perinatal outcome
}

\author{
Soumya Harikumar, Aparna Rajesh* \\ Department of Obstetrics and Gynecology, KS Hegde Medical Academy, Mangalore, Karnataka, India
}

Received: 23 November 2017

Accepted: 08 January 2018

\section{*Correspondence: \\ Dr. Aparna Rajesh, \\ E-mail: drpannarajesh@gmail.com}

Copyright: () the author(s), publisher and licensee Medip Academy. This is an open-access article distributed under the terms of the Creative Commons Attribution Non-Commercial License, which permits unrestricted non-commercial use, distribution, and reproduction in any medium, provided the original work is properly cited.

\begin{abstract}
Background: The objective of this study is to find a correlation between the presence of MSAF in mothers with comorbidities like PIH and GDM and to study the fetal heart variability in cases with MSAF and the significance of an admission test. This study also throws a light on the perinatal outcomes associated with MSAF.

Methods: 100 women in labor with Meconium stained amniotic fluid were taken in this study. An admission test was done for all patients, along with continuous fetal heart monitoring was done in the presence of MSAF. Effect of thin and thick meconium on fetus was studied. The cases with maternal co-morbidities were closely monitored along with the mode of delivery, Apgar score, birth weight, resuscitation of baby was studied. All the newborns born through meconium stained liquor were followed up to one week of neonatal life.

Results: Out of a total of 100 cases there was 60 cases with thick meconium with a non-reactive NST seen in $65 \%$ cases with thick MSAF and $32.5 \%$ cases with thin MSAF. $79 \%$ of cases with MSAF underwent emergency LSCS. The neonatal complications were more with thick meconium stained liquor accounting to $28.3 \%$ incidence of MAS, $23.3 \%$ of sepsis, $3.3 \%$ of pneumonitis and $21.7 \%$ of birth asphyxia.

Conclusions: This study ascertained the need for an admission test and continuous CTG monitoring in cases detected to have meconium stained amniotic fluid. Co-morbidities like GDM did have a small role to play though the incidence was not very high. The neonatal complications were more common among cases with thick meconium stained liquor and probably the use of procedures like amnioinfusion can bring down the incidence of perinatal morbidity along with the rate of caesarean sections.
\end{abstract}

Keywords: Meconium stained amniotic fluid, Non-stress test, Perinatal outcome

\section{INTRODUCTION}

There are two principal reasons why meconium is passed by the fetus-maturity and fetal compromise. Incidence of meconium stained liquor increases steadily from $10 \%$ at 36 weeks to $30 \%$ at 40 weeks and $50 \%$ at 42 weeks.

\section{Pathogenesis}

Under normal circumstances, the passage of meconium from the fetus into the amnion is prevented by the lack of intestinal peristalsis, which is caused by several factors, including low motilin levels, tonic contraction of the anal sphincter and a terminal cap of viscous meconium. Passage of meconium in the mature fetus is facilitated by myelination of nerve fibers and increase in parasympathetic tone and increase in the concentration of motilin. $^{1-3}$

Vagal stimulation produced by cord or head compression also may be associated with the passage of meconium in the absence of fetal distress. Term and post term neonates are more likely to pass meconium in response to such a stress than preterm neonates. Meconium passed as a maturational event is usually of thin consistency and Meconium aspiration syndrome and other serious complications occur infrequently in these circumstances. ${ }^{4}$ 
Because meconium seldom is observed preterm (Scott et al), its presence in amniotic fluid could reflect gastrointestinal maturity in late gestation. ${ }^{5}$

Now the definitions of birth asphyxia used are based on Apgar scores, umbilical cord acid/base status, time to spontaneous breathing, and the neurological/behavioral condition of the infant. Using these definitions, the incidence of birth asphyxia lies between 2.9 and 9/1000 deliveries Levene. ${ }^{6}$

Katz and Bowes stated that "when normal FHR patterns are found with meconium stained amniotic fluid the neonatal outcome is similar to neonates with clear fluid. ${ }^{7}$ Similarly, in infants with meconium stained amniotic fluid with antepartum signs of distress: neonatal outcomes are similar to those of non-meconium stained infants with similar FHR abnormalities. Perhaps the most important clinical value of meconium stained amniotic fluids is to alert the obstetrician, to look for further signs of fetal compromise. ${ }^{8}$

Umbilical cord erythropoietin concentrations are elevated in human pregnancies complicated by meconium stained amniotic fluid, suggesting an association between chronic hypoxemia and meconium passage (Jazayeri et al) ${ }^{9}$.

Such magnitude of different opinion was the object behind taking up of this study and the objective of this study is to find a correlation between the presence of MSAF in mothers with co- morbidities like PIH and GDM and to study the fetal heart variability in cases with MSAF and the significance of an admission test. This study also throws a light on the perinatal outcomes associated with MSAF.

\section{METHODS}

100 women in labor with meconium stained amniotic fluid were taken in this study taking all the inclusion and exclusion criteria into consideration. This study was conducted in KS HEGDE Charitable Hospital from October 2014 to September 2016. A detailed history with clinical examination along with investigations were done. An admission test was done for all patients, along with continuous fetal heart monitoring was done in the presence of MSAF. Effect of thin and thick meconium on fetus was studied. The cases with maternal co-morbidities were closely monitored along with the mode of delivery, Apgar score, birth weight, resuscitation of baby was studied.

All the newborns born through meconium stained liquor were followed up to one week of neonatal life.

\section{Inclusion criteria}

- $\quad$ Singleton pregnancy

- Gestational age >34 weeks

- Cephalic presentation
- Primi or multigravida, with meconium stained amniotic fluid,

- $\quad$ atent and active stages of labour,

- No pre-defined risk factors (medical illness complicating pregnancy), PROM

\section{Exclusion criteria}

- Multiple gestation,

- Gestational age <34 weeks,

- Malpresentations and congenital anomalies of the fetus.

Patients in labour with meconium stained amniotic fluid were selected following the inclusion and exclusion criteria. Detailed history was taken, and patients were carefully examined. These patients were clinically monitored during labour. The colour of amniotic fluid and degree of meconium was noted at the time of amniotomy or spontaneous rupture of membranes and at the time of delivery. The time interval between the detection of meconium and the time of delivery were noted.

Fetal heart rate abnormalities were recorded using cardiotocograph, after the detection of meconium.

Depending upon the degree of meconium, fetal heart rate abnormalities, stage of labour and other risk factors, the time and mode of delivery was decided. After delivery, the immediate fetal wellbeing was assessed by Apgar score at 1 minute and 5 minutes.

Details such as cord around the neck, meconium staining of the cord, finger nails, vernix caseosa, meconium smearing of the body were noted. Evidence of IUGR, posmaturity and congenital anomalies were looked for. After the delivery of placenta, meconium staining, infarcts, calcification were examined for. The perinatal outcome was evaluated based on NICU admissions, birth asphyxia, sepsis, MAS, respiratory distress, seizures, HIE, duration of NICU stay etc.

Babies were followed up in the neonatal period upto 1 month using reply cards, for any morbidity and mortality. The morbidity criteria were taken as MAS, chest infections, fever, sepsis, HIE, respiratory distress, seizures etc. The data is summarized as frequencies or percentages for categorical variables and as means and standard deviations and inter quartile ranges for continuous variables, depending on the distribution.

Differences between the treatment groups were compared by the chi-square for categorical variables and a twosample t-test for continuous variables. A p value of 0.05 or less was used for statistical significance.

Analyses were performed with SPSS software, version 17 for Windows. 


\section{Statistical analysis}

This was a prospective study done during a period of 23 months. The sampling technique was universal sampling. Pearsons correlation coefficient was obtained to study the relation. The $\mathrm{p}$ value of $<0.05$ was considered as significant.

\section{RESULTS}

Out of 1532 deliveries that took place during the study period there were 112 cases with meconium stained amniotic fluid out of which 100 cases were chosen that fit the inclusion criteria. The incidence was $7.3 \%$. Out of these 100 cases thick meconium was seen in 60 cases and thin meconium in 40 cases.

Table 1: Distribution based on period of gestation.

\begin{tabular}{|ll|l|}
\hline POG & No. of cases & Valid percent \\
\hline $37-38$ & 17 & $17 \%$ \\
\hline $38-39$ & 27 & $27 \%$ \\
\hline $39-40$ & 30 & $30 \%$ \\
\hline$>40$ & 26 & $26 \%$ \\
\hline Total & 100 & 100 \\
\hline
\end{tabular}

In this study the maximum percentage of meconium of $30 \%$ was noticed between 39 and 40 weeks of gestation. The number of post term pregnancies were less as they were induced in most of the cases. As the period of gestation increased, the incidence of thick meconium also increased, with maximum number of cases seen above 40 weeks of gestation.
Table 2: Relationship of POG with thick and thin meconium.

\begin{tabular}{|c|c|c|c|c|c|}
\hline \multicolumn{6}{|c|}{ Crosstab } \\
\hline & & & \multicolumn{2}{|c|}{$\begin{array}{l}\text { Meconium } \\
\text { staining }\end{array}$} & \multirow[t]{2}{*}{ Total } \\
\hline & & & Thick & Thin & \\
\hline \multirow{8}{*}{ POG } & \multirow[b]{2}{*}{$37-38$} & Count & 7 & 10 & 17 \\
\hline & & $\begin{array}{l}\% \text { within } \\
\text { meconium } \\
\text { staining }\end{array}$ & $11.7 \%$ & $25.0 \%$ & $17.0 \%$ \\
\hline & \multirow[b]{2}{*}{$38-39$} & Count & 17 & 10 & 27 \\
\hline & & $\begin{array}{l}\% \text { within } \\
\text { meconium } \\
\text { staining }\end{array}$ & $28.3 \%$ & $25.0 \%$ & $27.0 \%$ \\
\hline & \multirow[b]{2}{*}{$39-40$} & Count & 17 & 13 & 30 \\
\hline & & $\begin{array}{l}\% \text { within } \\
\text { meconium } \\
\text { staining }\end{array}$ & $28.3 \%$ & $32.5 \%$ & $30.0 \%$ \\
\hline & \multirow[b]{2}{*}{$>40$} & Count & 19 & 7 & 26 \\
\hline & & $\begin{array}{l}\% \text { within } \\
\text { meconium } \\
\text { staining }\end{array}$ & $31.7 \%$ & $17.5 \%$ & $26.0 \%$ \\
\hline \multirow{2}{*}{\multicolumn{2}{|c|}{ Total }} & Count & 60 & 40 & 100 \\
\hline & & $\begin{array}{l}\% \text { within } \\
\text { meconium } \\
\text { staining }\end{array}$ & $100.0 \%$ & $100.0 \%$ & $100.0 \%$ \\
\hline \multicolumn{6}{|c|}{ Chi-square tests } \\
\hline & & Value & df & \multicolumn{2}{|c|}{$\begin{array}{l}\text { Asymp sig } \\
\text { (2-sided) }\end{array}$} \\
\hline \multicolumn{2}{|c|}{$\begin{array}{l}\text { Pearson chi- } \\
\text { square }\end{array}$} & 4.600 & 3 & \multicolumn{2}{|l|}{0.204} \\
\hline \multicolumn{2}{|c|}{$\begin{array}{l}\text { No. of valid } \\
\text { cases }\end{array}$} & 100 & & & \\
\hline
\end{tabular}

Table 3: NST pattern.

\begin{tabular}{|c|c|c|c|c|c|}
\hline \multicolumn{6}{|c|}{ Crosstab } \\
\hline & & & \multicolumn{2}{|c|}{ Meconium staining } & \multirow[t]{2}{*}{ Total } \\
\hline & & & Thick & Thin & \\
\hline \multirow[t]{4}{*}{ NST } & \multirow[t]{2}{*}{ Non-reactive } & Count & 39 & 13 & 52 \\
\hline & & $\%$ within meconium staining & $65.0 \%$ & $32.5 \%$ & $52.0 \%$ \\
\hline & \multirow[t]{2}{*}{ Reactive } & Count & 21 & 27 & 48 \\
\hline & & $\%$ within meconium staining & $35.0 \%$ & $67.5 \%$ & $48.0 \%$ \\
\hline \multirow{2}{*}{\multicolumn{2}{|c|}{ Total }} & Count & 60 & 40 & 100 \\
\hline & & $\%$ within meconium staining & $100.0 \%$ & $100.0 \%$ & $100.0 \%$ \\
\hline
\end{tabular}

Table 4: Mode of delivery.

\begin{tabular}{|c|c|c|c|c|c|}
\hline & & & \multicolumn{2}{|c|}{ Meconium staining } & \multirow{2}{*}{ Total } \\
\hline & & & Thick & Thin & \\
\hline \multirow{6}{*}{ Mode of delivery } & \multirow{2}{*}{ Lscs } & Count & 55 & 24 & 79 \\
\hline & & $\%$ within meconium staining & $91.7 \%$ & $60.0 \%$ & $79.0 \%$ \\
\hline & \multirow{2}{*}{ Nvd } & Count & 5 & 14 & 19 \\
\hline & & $\%$ within meconium staining & $8.3 \%$ & $35.0 \%$ & $19.0 \%$ \\
\hline & \multirow{2}{*}{ Vaccum } & Count & 0 & 2 & 2 \\
\hline & & $\%$ within meconium staining & $0.0 \%$ & $5.0 \%$ & $2.0 \%$ \\
\hline \multirow{2}{*}{ Total } & & Count & 60 & 40 & 100 \\
\hline & & $\%$ within meconium staining & $100.0 \%$ & $100.0 \%$ & $100.0 \%$ \\
\hline
\end{tabular}


Table 5: Mode of delivery in relation to stage of labor in which meconium was first noticed.

\begin{tabular}{|c|c|c|c|c|c|c|c|}
\hline \multirow[t]{2}{*}{ Gravida } & \multirow[t]{2}{*}{ PV } & & & & \multicolumn{2}{|c|}{$\begin{array}{l}\text { Meconium } \\
\text { staining }\end{array}$} & \multirow[t]{2}{*}{ Total } \\
\hline & & & & & Thick & Thin & \\
\hline \multirow{10}{*}{ Multi } & \multirow{6}{*}{ Active } & \multirow{4}{*}{$\begin{array}{l}\text { Mode of } \\
\text { delivery }\end{array}$} & \multirow{2}{*}{ LSCS } & Count & 4 & 1 & 5 \\
\hline & & & & $\%$ within meconium staining & $80.0 \%$ & $12.5 \%$ & $38.5 \%$ \\
\hline & & & \multirow{2}{*}{ NVD } & Count & 1 & 7 & 8 \\
\hline & & & & $\%$ within meconium staining & $20.0 \%$ & $87.5 \%$ & $61.5 \%$ \\
\hline & & \multirow{2}{*}{ Total } & & Count & 5 & 8 & 13 \\
\hline & & & & $\%$ within meconium staining & $100.0 \%$ & $100.0 \%$ & $100.0 \%$ \\
\hline & \multirow{4}{*}{ Latent } & \multirow{2}{*}{$\begin{array}{l}\text { Mode of } \\
\text { delivery }\end{array}$} & \multirow{2}{*}{ LSCS } & Count & 11 & 7 & 18 \\
\hline & & & & $\%$ within meconium staining & $100.0 \%$ & $100.0 \%$ & $100.0 \%$ \\
\hline & & \multirow{2}{*}{ Total } & & Count & 11 & 7 & 18 \\
\hline & & & & $\%$ within meconium staining & $100.0 \%$ & $100.0 \%$ & $100.0 \%$ \\
\hline \multirow{16}{*}{ Primi } & \multirow{4}{*}{$\begin{array}{l}\text { 2nd } \\
\text { stage }\end{array}$} & \multirow{2}{*}{$\begin{array}{l}\text { Mode of } \\
\text { delivery }\end{array}$} & \multirow{2}{*}{ LSCS } & Count & 3 & & 3 \\
\hline & & & & $\%$ within meconium staining & $100.0 \%$ & & $100.0 \%$ \\
\hline & & \multirow{2}{*}{ Total } & & Count & 3 & & 3 \\
\hline & & & & $\%$ within meconium staining & $100.0 \%$ & & $100.0 \%$ \\
\hline & \multirow{8}{*}{ Active } & \multirow{6}{*}{$\begin{array}{l}\text { Mode of } \\
\text { delivery }\end{array}$} & \multirow{2}{*}{ LSCS } & Count & 10 & 3 & 13 \\
\hline & & & & $\%$ within meconium staining & $71.4 \%$ & $25.0 \%$ & $50.0 \%$ \\
\hline & & & \multirow{2}{*}{ NVD } & Count & 4 & 7 & 11 \\
\hline & & & & $\%$ within meconium staining & $28.6 \%$ & $58.3 \%$ & $42.3 \%$ \\
\hline & & & \multirow{2}{*}{ Vaccum } & Count & 0 & 2 & 2 \\
\hline & & & & $\%$ within meconium staining & $0.0 \%$ & $16.7 \%$ & $7.7 \%$ \\
\hline & & \multirow{2}{*}{ Total } & & Count & 14 & 12 & 26 \\
\hline & & & & $\%$ within meconium staining & $100.0 \%$ & $100.0 \%$ & $100.0 \%$ \\
\hline & \multirow{4}{*}{ Latent } & \multirow{2}{*}{$\begin{array}{l}\text { Mode of } \\
\text { delivery }\end{array}$} & \multirow{2}{*}{ LSCS } & Count & 27 & 13 & 40 \\
\hline & & & & $\%$ within meconium staining & $100.0 \%$ & $100.0 \%$ & $100.0 \%$ \\
\hline & & \multirow{2}{*}{ Total } & & Count & 27 & 13 & 40 \\
\hline & & & & $\%$ within meconium staining & $100.0 \%$ & $100.0 \%$ & $100.0 \%$ \\
\hline
\end{tabular}

Table 6: NICU admission (in relation to thick and thin meconium).

\begin{tabular}{|c|c|c|c|c|c|}
\hline \multicolumn{6}{|c|}{ Crosstab } \\
\hline & & & \multicolumn{2}{|c|}{ Meconium staining } & \multirow{2}{*}{ Total } \\
\hline & & & Thick & Thin & \\
\hline \multirow{4}{*}{ NICU } & \multirow{2}{*}{ No } & Count & 37 & 24 & 61 \\
\hline & & $\%$ within meconium staining & $61.7 \%$ & $60.0 \%$ & $61.0 \%$ \\
\hline & \multirow{2}{*}{ Yes } & Count & 23 & 16 & 39 \\
\hline & & $\%$ within meconium staining & $38.3 \%$ & $40.0 \%$ & $39.0 \%$ \\
\hline \multirow{3}{*}{\multicolumn{2}{|c|}{ Total }} & Count & 60 & 40 & 100 \\
\hline & & $\%$ within meconium staining & $100.0 \%$ & $100.0 \%$ & $100.0 \%$ \\
\hline & & Value & Asymp & ded) & \\
\hline \multicolumn{2}{|c|}{ Pearson chi-square } & 0.028 & 0.867 & & \\
\hline \multicolumn{2}{|c|}{$\mathrm{N}$ of valid cases } & 100 & & & \\
\hline
\end{tabular}

\section{NST pattern}

$52 \%$ of patients with meconium stained liquor had a nonreactive NST among the 100 cases. There were 52 cases with a non-reactive NST of which 39 were among cases with thick meconium stained liquor group. The $\mathrm{p}$ value is 0.001 and is a highly significant finding. In the 100 cases in this study $79 \%$ of the cases went for LSCS. Majority of the cases were taken up for an emergency LSCS due to the presence of thick meconium.

This was more in case of primigravidas in whom the thick meconium was observed earlier in labor as can be seen in the table 6 . The $p$ value was 0.001 and hence was a significant finding. Most of the babies did not require NICU admission. Out of the 100 babies born 39 babies 
required NICU admission out of which 23 were born through thick meconium. Most of the babies were kept for observation in view of tachypnea. Most of the babies were by bedside by the $4^{\text {th }}$ postnatal day.

There was no appreciable difference in the APGAR score of 1 minute in both thin and thick meconium in this study. The babies had cried immediately, though they were observed to have tachypnea, grunting, etc.

Both the thin and thick meconium had equal number or cases in the scores 0-3 and 4-6.

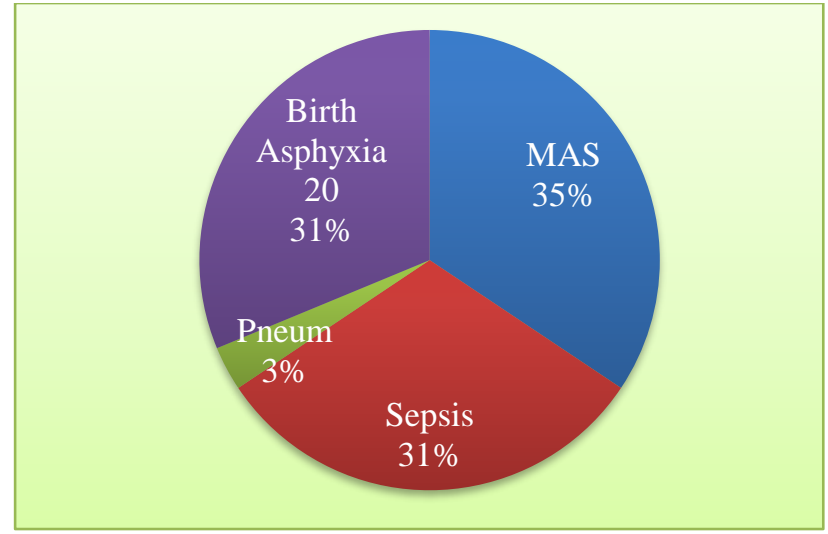

Figure 1: Overall incidence of perinatal morbidity.

Table 7: Relation between APGAR score (score-1) and meconium stained liquor.

\begin{tabular}{|c|c|c|c|c|c|}
\hline \multicolumn{6}{|l|}{ Crosstab } \\
\hline & & & \multicolumn{2}{|c|}{ Meconium staining } & \multirow{2}{*}{ Total } \\
\hline & & & Thick & Thin & \\
\hline \multirow{6}{*}{ Apgar (1) } & \multirow{2}{*}{$0-3$} & Count & 1 & 1 & 2 \\
\hline & & $\%$ within meconium staining & $1.7 \%$ & $2.5 \%$ & $2.0 \%$ \\
\hline & \multirow{2}{*}{$4-6$} & Count & 3 & 3 & 6 \\
\hline & & $\%$ within meconium staining & $5.0 \%$ & $7.5 \%$ & $6.0 \%$ \\
\hline & \multirow{2}{*}{$7-10$} & Count & 56 & 36 & 92 \\
\hline & & $\%$ within meconium staining & $93.3 \%$ & $90.0 \%$ & $92.0 \%$ \\
\hline \multirow{2}{*}{\multicolumn{2}{|c|}{ Total }} & Count & 60 & 40 & 100 \\
\hline & & $\%$ within meconium staining & $100.0 \%$ & $100.0 \%$ & $100.0 \%$ \\
\hline \multirow{2}{*}{\multicolumn{2}{|c|}{ Pearson chi-square }} & balue & \multicolumn{3}{|c|}{ Asymp Sig (2-sided) } \\
\hline & & 0.362 & 0.834 & & \\
\hline \multicolumn{2}{|c|}{$\mathrm{N}$ of valid cases } & 100 & & & \\
\hline
\end{tabular}

Table 8: Relation between APGAR score (score 5) and meconium stained liquor.

\begin{tabular}{|c|c|c|c|c|c|}
\hline \multicolumn{6}{|l|}{ Crosstab } \\
\hline & & & Meconit & aining & \\
\hline & & & Thick & Thin & Total \\
\hline \multirow{4}{*}{ Apgar (5) } & \multirow{2}{*}{$4-6$} & Count & 1 & 0 & 1 \\
\hline & & $\%$ within meconium staining & $1.7 \%$ & $0.0 \%$ & $1.0 \%$ \\
\hline & \multirow{2}{*}{$7-10$} & Count & 59 & 40 & 99 \\
\hline & & $\%$ within meconium staining & $98.3 \%$ & $100.0 \%$ & $99.0 \%$ \\
\hline \multirow{3}{*}{ Total } & & Count & 60 & 40 & 100 \\
\hline & & $\%$ within meconium staining & $100.0 \%$ & $100.0 \%$ & $100.0 \%$ \\
\hline & & value & \multicolumn{3}{|c|}{ Asymp Sig (2-sided) } \\
\hline \multicolumn{2}{|c|}{ Pearson chi-square } & 0.673 & \multicolumn{3}{|l|}{0.412} \\
\hline \multicolumn{2}{|c|}{$\mathrm{N}$ of valid cases } & 100 & & & \\
\hline
\end{tabular}

There were no significant findings in the APGAR score at 5 minutes. In both 1 minute and 5-minute APGAR scores thin meconium had lower APGAR scores. At 5 minutes there was only one baby born through thick meconium remained to have a low APGAR score. There was no statistical significance between $b$. wt and incidence of meconium stained liquor. Maximum number of cases of meconium stained liquor was seen in b. wt between $2.5 \mathrm{~kg}$ to $3.5 \mathrm{~kg}$.

The incidence of thick meconium was more than thin meconium in this group. There were 44 cases with thick meconium and 32 cases with thin meconium stained liquor. There was one case of neonatal death, the baby was born through thick meconium. Out of the 100 cases 
studied in this study 82 babies were discharged fully recovered out of which 49 babies were born through thick meconium and 33 babies were born through thin meconium. There were 17 cases that was still recovering, of which 10 were born through thick meconium and the remaining through thin meconium.

Table 9: Condition at discharge.

\begin{tabular}{|c|c|c|c|c|c|}
\hline \multicolumn{6}{|l|}{ Crosstab } \\
\hline & & & \multicolumn{2}{|c|}{ Meconium staining } & \multirow{2}{*}{ Total } \\
\hline & & & Thick & Thin & \\
\hline \multirow{6}{*}{$\begin{array}{l}\text { Condition at } \\
\text { discharge }\end{array}$} & \multirow{2}{*}{ Normal } & Count & 49 & 33 & 82 \\
\hline & & $\%$ within meconium staining & $81.7 \%$ & $82.5 \%$ & $82.0 \%$ \\
\hline & \multirow{2}{*}{$\begin{array}{l}\text { Neonatal } \\
\text { death }\end{array}$} & Count & 1 & 0 & 1 \\
\hline & & $\%$ within meconium staining & $1.7 \%$ & $0.0 \%$ & $1.0 \%$ \\
\hline & \multirow{2}{*}{ Recovering } & Count & 10 & 7 & 17 \\
\hline & & $\%$ within meconium staining & $16.7 \%$ & $17.5 \%$ & $17.0 \%$ \\
\hline \multirow{3}{*}{\multicolumn{2}{|c|}{ Total }} & Count & 60 & 40 & 100 \\
\hline & & $\%$ within meconium staining & $100.0 \%$ & $100.0 \%$ & $100.0 \%$ \\
\hline & & Value & Asymp & -sided) & \\
\hline \multicolumn{2}{|c|}{ Pearson chi-square } & 0.679 & 0.712 & & \\
\hline \multicolumn{2}{|c|}{$\mathrm{N}$ of valid cases } & 100 & & & \\
\hline
\end{tabular}

Table 10: Incidence of meconium stained liquor in cases with PROM.

\begin{tabular}{|c|c|c|c|c|c|}
\hline \multicolumn{6}{|l|}{ Crosstab } \\
\hline & & & Meconiu & & \\
\hline & & & Thick & Thin & Total \\
\hline \multirow{4}{*}{ Prom } & \multirow{2}{*}{$\mathrm{N}$} & Count & 47 & 32 & 79 \\
\hline & & $\%$ within meconium staining & $78.3 \%$ & $80.0 \%$ & $79.0 \%$ \\
\hline & \multirow{2}{*}{$\mathrm{Y}$} & Count & 13 & 8 & 21 \\
\hline & & $\%$ within meconium staining & $21.7 \%$ & $20.0 \%$ & $21.0 \%$ \\
\hline \multirow{3}{*}{ Total } & & Count & 60 & 40 & 100 \\
\hline & & $\%$ within meconium staining & $100.0 \%$ & $100.0 \%$ & $100.0 \%$ \\
\hline & & Value & \multicolumn{2}{|c|}{ Asymp Sig (2-sided) } & \\
\hline \multicolumn{2}{|l|}{ Pearson chi-square } & 0.040 & 0.841 & & \\
\hline \multicolumn{2}{|l|}{$\mathrm{N}$ of valid cases } & 100 & & & \\
\hline
\end{tabular}

Table 11: Incidence of meconium stained liquor among mothers with PIH.

\begin{tabular}{|c|c|c|c|c|c|}
\hline \multicolumn{6}{|c|}{ Crosstab } \\
\hline & & & \multicolumn{2}{|c|}{ Meconium staining } & \multirow{2}{*}{ Total } \\
\hline & & & Thick & Thin & \\
\hline \multirow{4}{*}{$\mathrm{PIH}$} & \multirow{2}{*}{$\mathrm{N}$} & Count & 57 & 39 & 96 \\
\hline & & $\%$ within meconium staining & $95.0 \%$ & $97.5 \%$ & $96.0 \%$ \\
\hline & \multirow{2}{*}{$\mathrm{Y}$} & Count & 3 & 1 & 4 \\
\hline & & $\%$ within meconium staining & $5.0 \%$ & $2.5 \%$ & $4.0 \%$ \\
\hline \multirow{2}{*}{\multicolumn{2}{|c|}{ Total }} & Count & 60 & 40 & 100 \\
\hline & & $\%$ within meconium staining & $100.0 \%$ & $100.0 \%$ & $100.0 \%$ \\
\hline \multicolumn{6}{|c|}{ Chi-square tests } \\
\hline & & Value & Df & \multicolumn{2}{|c|}{ Asymp Sig (2-sided) } \\
\hline \multicolumn{2}{|c|}{ Pearson chi-square } & 0.391 & 1 & \multicolumn{2}{|c|}{0.532} \\
\hline \multicolumn{2}{|c|}{$\mathrm{N}$ of valid cases } & 100 & & & \\
\hline b. Cor & & & & & \\
\hline
\end{tabular}

\section{Maternal factors and its relation to meconium stained}

There was no significant increase in the incidence in the meconium stained liquor among women with premature rupture of membranes. There were 21 cases with meconium stained liquor among the PROM group of 
which 13 cases were thick meconium stained liquor and 8 were thin meconium stained liquor. There were only 4 cases of among the 100 cases where meconium was noticed among mothers with PIH of which 3 were thick meconium and one was thin meconium. This shows no statistical significance in this study. There was a $4 \%$ incidence of meconium stained liquor among PIH patients in this study. Among the 100 cases studied there were only 11 cases with GDM of which 6 cases were thick meconium and 5 cases were thin meconium stained liquor. Meconium stained liquor had a $11 \%$ incidence among the 100 cases studied in this study

Table 12: Incidence of meconium stained liquor among women with GDM.

\begin{tabular}{|c|c|c|c|c|c|}
\hline \multicolumn{6}{|c|}{ Crosstab } \\
\hline & & & Meconi & ing & \\
\hline & & & Thick & Thin & Total \\
\hline \multirow{4}{*}{ Gdm } & \multirow{2}{*}{$\mathrm{N}$} & Count & 54 & 35 & 89 \\
\hline & & $\%$ within meconium staining & $90.0 \%$ & $87.5 \%$ & $89.0 \%$ \\
\hline & \multirow{2}{*}{$\mathrm{Y}$} & Count & 6 & 5 & 11 \\
\hline & & $\%$ within meconium staining & $10.0 \%$ & $12.5 \%$ & $11.0 \%$ \\
\hline \multirow{3}{*}{\multicolumn{2}{|c|}{ Total }} & Count & 60 & 40 & 100 \\
\hline & & $\%$ within meconium staining & $100.0 \%$ & $100.0 \%$ & $100.0 \%$ \\
\hline & & Value & Asymp & ed) & \\
\hline \multicolumn{2}{|c|}{ Pearson chi-square } & 0.153 & 0.695 & & \\
\hline \multicolumn{2}{|c|}{$\mathrm{N}$ of valid cases } & 100 & & & \\
\hline
\end{tabular}

\section{DISCUSSION}

In the present study the incidence was $7.3 \%$. Out of total of 1532 deliveries that took place during the study period there were 112 cases with meconium stained amniotic fluid out of which 100 cases were taken in this study. In the present study the incidence of thin MSAF is $40 \%$ and thick $60 \%$. The incidence of thick meconium stained liquor was more in this study (60\%)in comparison with the studies conducted by Debdas and Arun which was $21.25 \%$ and $48.85 \%$ respectively. ${ }^{10} 100$ cases of meconium stained were taken to evaluate perinatal outcome in MSAF. Meconium stained liquor were divided into two groups based on the type of staining: thin and thick.

Out of these 100 cases, thin meconium staining was seen in 40 cases $(40 \%)$ and $60(60 \%)$ cases had thick meconium stained liquor. Parity and maternal age were independent factors for type of meconium stained amniotic fluid. $44 \%$ of the mothers were less than 25 years of age, $41 \%$ were between $26-30$ years and $15 \%$ were more than 30 years of age. The present study correlates with the study conducted by Ghokroo K and Sandhu et al which was $56 \%$ and $80 \%$ among women between $20-30$ years and $5.30 \%$ and $12 \%$ for ladies more than 30 years. ${ }^{11}$ The probable explanation is that, this is the age group where most of the Indian women conceive and most of the primigravidas are in this age group in our setup. $69 \%$ were primi gravida and $31 \%$ were multigravidas. In the present study highest incidence of MSAF was seen among primi gravidas i.e., 69\%. In comparison with study done by Kamala et al we have got similar findings that the incidence of meconium stained liquor is more among primi gravidas than multigravida mostly because of the fact that they carry the pregnancy to term and they have a longer duration of labor. ${ }^{11}$ MSAF seen in $21 \%$ of cases with PROM, $4 \%$ cases with PIH, $11 \%$ cases with GDM and $2 \%$ cases with previous LSCS as compared to a study conducted by Vinaya pendse et al who had a percentage of $26.5 \%$ for PIH and $6 \%$ for PROM as against the present findings. ${ }^{12} 35 \%$ cases with thin MSAF had normal vaginal delivery, $5 \%$ had vacuum delivery, and $60 \%$ had LSCS compared with thick meconium were $8.3 \%$ had normal vaginal delivery, and $91.7 \%$ LSCS. There was a significant $\mathrm{p}$ value of 0.001 , which proved that there is very high incidence of LSCS done among patients with meconium stained liquor. Similar results were also seen in studies conducted by Bhide ss et al. ${ }^{13}$

Munrokerr is of the opinion that thick meconium staining revealed at the time of induction by amniotomy, or in early labour is so omnious that he generally regards it as an indication for caesarean section. NST pattern of nonreactive were more in case of thick meconium accounting for $65 \%$ as compared to non-reactive in case of thin meconium accounting for $32.5 \%$. The $\mathrm{p}$ value was 0.001 which was highly significant and similar results were seen in a study done by Rosairo et al. ${ }^{14}$ Number of babies requiring NICU admission were 23 in case of thick meconium accounting to $38.3 \%$ and 16 in case of thin meconium babies accounting to $40 \%$. Most of the babies were kept for observation for about 24 hours in view of tachypnoea, grunting etc. which usually settled within 24 hours. Study conducted by Goud P et al showed a NICU admission of $10.8 \%$ among thin and $54.9 \%$ NICU admission. ${ }^{15}$

Perinatal morbidity was more among thick meconium 
stained liquor than in thin meconium stained liquor. The incidence of MAS was $28.3 \%$ in thick MSAF compared to $12.5 \%$ in thin MSAF. Sepsis was seen in $23.3 \%$ cases with thick MSAF compared with $15.5 \%$ cases in thin MSAF. Pneumonitis was seen in 3.35 cases with thick MSAF and none in thin MSAF. Birth asphyxia was seen among $21.7 \%$ cases with thick MSAF as compared to $17.5 \%$ with thin MSAF. Perinatal mortality was 3\% in a study conducted by Debdas et al and $7.7 \%$ in a study by goud and krishna et al. ${ }^{10,15}$ Thick meconium stained liquor, which caused MAS in a neonate, was the cause for the neonatal death. Perinatal mortality was $1 \%$ in this study.

Narang et al, is of the opinion that in the group with thin meconium the babies are not generally depressed at birth and do not have any higher perinatal mortality rate in comparision to those with clear liquor. ${ }^{16}$

\section{CONCLUSION}

Overall incidence of MSAF during labor in the present study is $7.3 \%$. 1 minute and 5-minute Apgar score was almost the same in both the thin and thick meconium stained liquor group. There by suggesting that both thin and thick meconium can lead to perinatal complications has one has to be vigilant. Birth asphyxia, pneumonitis, MAS and sepsis were more common among thick meconium stained liquor. Non-reactive NST was more common with thick meconium stained liquor ascertaining the need for an admission test. This study also proves that there is an increased incidence of LSCS among meconium stained liquor as it always is an enigma for the obstetrician.

The study confirmed that our clinical impression with meconium stained amniotic fluid adversely affected fetal outcome. Increased incidence in morbidity and mortality in the present study is associated with thick meconium i.e., MAS was seen in 17 cases of thick meconium and 5 cases of thin meconium. Birth asphyxia was seen in 13 cases of thick meconium and 7 cases of thin meconium. Pneumonitis was seen in 2 cases of thick meconium and none in thin MSAF, sepsis was seen in 17 cases with thick MSAF and 5 with thin MSAF. This study ascertains the need for an Admission test for all patients. A reactive NST has a good prognosis for a minimum of four hours Most of the centers of our country lack facilities of electronic FHR monitoring and fetal scalp blood studies. In such conditions, clinical evaluation of cases is necessary.Thick meconium stained amniotic fluid is associated with increased rate of intervention, neonatal morbidity and mortality compared with thin MSAF. Meconium stained amniotic fluid is not an indicator for fetal distress especially thin MSAF but with correlation with non-reassuring fetal heart rate should be taken as potential danger sign for the baby. Continuous intra partum FHR monitoring, gradation of meconium, availability of NST and progress of labor should be considered in the management of meconium stained group. Admission to delivery interval, as well as stage of labor is important in deciding the mode of delivery and prevention of perinatal morbidity.

\section{ACKNOWLEDGMENTS}

Authors express their deepest gratitude to their teacher and guide, Dr. Aparna Rajesh, Professor, Department of Obstetrics and Gynecology, K. S. Hegde Medical Academy, Mangalore, for her valuable suggestions and guidance and to Dr. Prince Lenin who helped the authors throughout the study

Funding: No funding sources Conflict of interest: None declared

Ethical approval: The study was approved by the Institutional Ethics Committee

\section{REFERENCES}

1. Carveno CA, Blackwell SC, Berry H. Meconium passage in term pregnancies occurs independent of AF volume. Am J Obstet Gynecol. 2000;182(10)(2):109.

2. Gokhroo K, Sharma U, Sharma M. Various maternal factors responsible for meconium stained amniotic fluid. J Obstet Gynaecol India. 2001;52(6):40.

3. Lucas A, Christofides ND, Adrian TE, Bloom SR, Aynsley-Green A. Fetal distress, meconium, and motilin. The Lancet. 1979;313(8118):718.

4. Williams Textbook of Obstetrics. Murphy and Associates. 23 ${ }^{\text {rd }}$ Edition. McGraw-Hill Professional Publishing. 2009:431.

5. Scott H, Walker M, Gruslin A. Significance of meconium-stained amniotic fluid in the preterm population. J Perinatol. 2001;21(3):174.

6. Levene MI, Fenton AC, Evans DH, Archer LN, Shortland DB, Gibson NA. Severe birth asphyxia and abnormal cerebral blood-flow velocity. Developmental Med Child Neurol. 1989;31(4):42734.

7. Katz VL, Bowes WA. Meconium aspiration syndrome: reflections on a murky subject. Am J Obstet Gynecol. 1992;166(1):171-83.

8. Sandhu SK, Singh J, Khura H, Kaur H. Critical evaluation of meconium staining of amniotic fluid and fetal outcome. Obstet Gynecol India. 1993;43:528-53.

9. Jazayeri A, Politz L, Tsibris JC, Queen T, Spellacy WN. Fetal erythropoietin levels in pregnancies complicated by meconium passage: does meconium suggest fetal hypoxia?. Am J Obstet Gynecol. 2000;183(1):188-90.

10. Debdas AK, Kaur T. Meconium stained liquor: reappraisal. J Obstet Gynaecol India. 1981;31:924-9.

11. Gokhroo K, Ushasharma. Various maternal factors responsible for meconium stained amniotic fluid. J Obstet Gynecol India. 2001;51:6. 
12. Pendse V, Meconium MS. Stained liquor amnii: its significance and effect on fetal outcome. J Obstet Gynecol India. 1983;33:66-9.

13. Bhide SS, Shendurnikar N, Aiyer S, Baxi SR. Neonatal outcome after meconium stained amniotic fluid. J Obstet Gynecol India. 1993;44:933-5.

14. Rosario MC, Seshadri L. Meconium staining of amniotic fluid in low risk parturient. J Obstet Gynecol India. 1996;46:642-6.
15. Goud P, Krishna U. Significance of Meconium stained amniotic fluid in labour. J Obst Gynecol India. 1989;39:523-6.

16. Narang A, Nair PM, Bhakoo ON, Vashisht K. Management of meconium stained amniotic fluid: a team approach. Indian pediatrics. 1993;30:9-13.

Cite this article as: Harikumar S. Study on Meconium stained fluid-perinatal outcome. Int J Reprod Contracept Obstet Gynecol 2018;7:587-95. 